\title{
White matter abnormality in cerebral atrophy: clinicoradiological correlations
}

\author{
A R VAlentine, I F MOSELEY, AND B E KENDALL \\ Lysholm Radiological Department, National Hospital, Queen Square, London
}

SUMMARY The computed tomography (CT) scans in $1.6 \%$ of patients with cerebral atrophy showed the additional feature of areas of reduced attenuation in the deep cerebral white matter. Analysis of the clinical data showed a significant association with both hypertension and dementia. État criblé in vascular hypertension is suggested as the possible cause.

We have noted during routine viewing of computed tomography (CT) scans that a small number of patients with otherwise typical cerebral atrophy have abnormally low attenuation in the deep hemispheric white matter. The only reference to such an association is by Pasquini et al, ${ }^{1}$ who stated that periventricular reduced attenuation occurred in two $(0.8 \%)$ of their cases of cerebral atrophy; both these patients, however, showed radionuclide cisternographic evidence of communicating hydrocephalus. In our patients there were no features of communicating hydrocephalus and the distribution and appearance of the white matter low attenuation (WMLA) is unlike that which occurs with hydrocephalus.

This paper records the clinical, laboratory, and CT features of this group of patients in an effort to establish the significance of the reduced attenuation and the nature of the underlying disease process.

\section{Patients and methods}

CT scans of 1700 patients seen at the National Hospital, Queen Square, in 1976-8 and previously reported as showing cerebral atrophy were retrieved and those with WMLA selected. Patients in whom focal lesions were present or who had undergone neurosurgery or external irradiation were excluded.

The scans were re-examined to confirm the presence and distribution of WMLA; the ventri-

Address for reprints: Dr BE Kendall, Lysholm Radiological Department, The National Hospital, Queen Square, London WC1N 3BG.

Accepted 24 September 1979 cular size (by Evans's ratio and inspection) and the degree of cortical atrophy (assessed on a scale of 0 to +++ ) were noted. The case records were reviewed and the age and sex of the patient, the presenting symptoms (especially dementia, gait disturbance, urinary problems, headache), medical history (especially head injury, epilepsy, and drug or alcohol abuse), and the findings on neurological and general examination, including any evidence of cardiovascular disease, the blood pressure, and the haemoglobin concentration, were tabulated.

\section{Results}

There were 28 patients ( $1.6 \%$ of those reviewed), 16 men and 12 women, with a mean age of 65.4 years (range 40-83).

Table 1 summarises the findings.

SCAN APPEARANCES:

$W M L A$ This was always bilateral and usually symmetrical, though in one case capsular involvement was unilateral. The region around the frontal horn was always affected; the anterior limb of the internal or external capsule was affected in 21 patients $(75 \%)$, the parietal centrum semiovale in $15(54 \%)$, and the region around the cella media in $15(54 \%)$. We divided the patients into those showing only frontal and capsular WMLA (group A, 10 patients) and those with more widespread involvement (group B, 18 patients).

Ventricular size Although Evans's ratio was increased (greater than $0 \cdot 3$ ) in only eight cases, it was considered that all cases showed at least 
Table 1 Clinical data-CT analysis

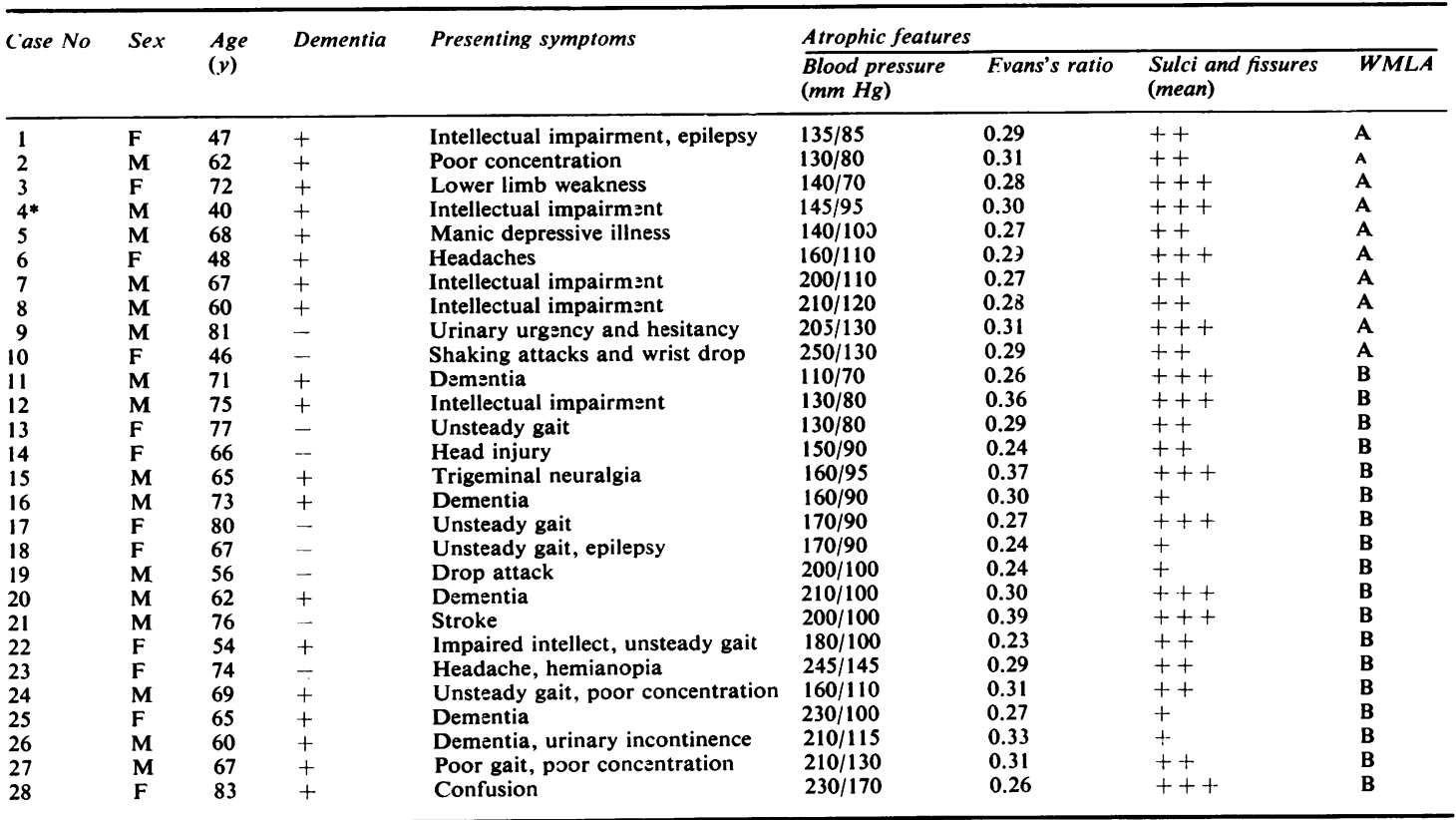

*History of severe hypertension as a medical student.

mild ventricular enlargement, and were therefore regarded cerebral rather than purely cortical atrophy. The mean Evans's ratio in both groups was $0 \cdot 29$, indicating the lack of correlation between ventricular size and extent of WMLA and also emphasising that ventricular enlargement was not a prominent feature.

Cortical atrophy There was, moreover, no correlation between the degree of cortical atrophy and the extent of the WMLA. The mean sulcal size was $2 \cdot 4+$ in group A and $2 \cdot 1+$ in group B. Similar assessment of size of Sylvian fissures showed no difference between the two groups.

\section{CLINICAL FEATURES}

Age The relatively advanced age of most of the patients is reflected in the mean (65.4 years); only six were aged under 60 . The mean age of the patients in group $A$ was 60 , while those in group B, with the more widespread WMLA, had a mean age of 69 .

Presenting features and neurological examination Dementia was present in $19(68 \%)$ of the patients. Gait disturbance was complained of by 15 patients, 11 of whom were demented; physical examination showed gait ataxia in eight of them, and cerebellar signs in two. Five patients were illsontinent, three of whom also had gait disturbance. Seven patients had hemisyndromes, and of these five were dysphasic and two showed primitive reflexes. There was no correlation between the extent of WMLA and a history of previous head injury, loss of consciousness, epilepsy, or headache. Haemoglobin concentration was abnormal in only one patient who subsequently died of renal carcinoma.

Cardiovascular system The diastolic blood pressure was $100 \mathrm{~mm} \mathrm{Hg}$ or above (range 100170 ) in 20 patients $(71 \%), 90-99 \mathrm{~mm} \mathrm{Hg}$ in four, and less than $90 \mathrm{~mm} \mathrm{Hg}$ in only four. There was no difference between the mean diastolic blood

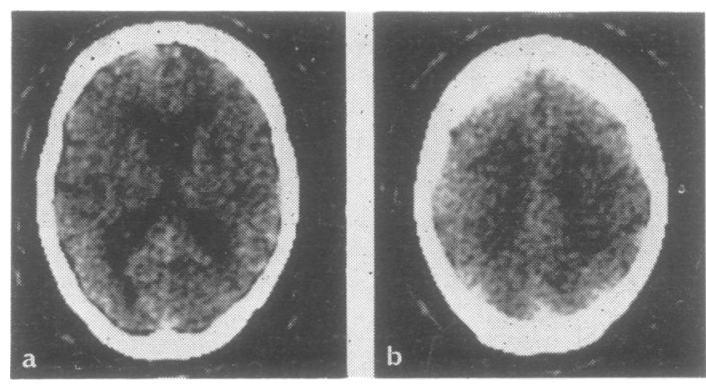

Fig 1 Typical case showing mild atrophic features. Reduced attenuation in frontal capsular and parietal regions. 

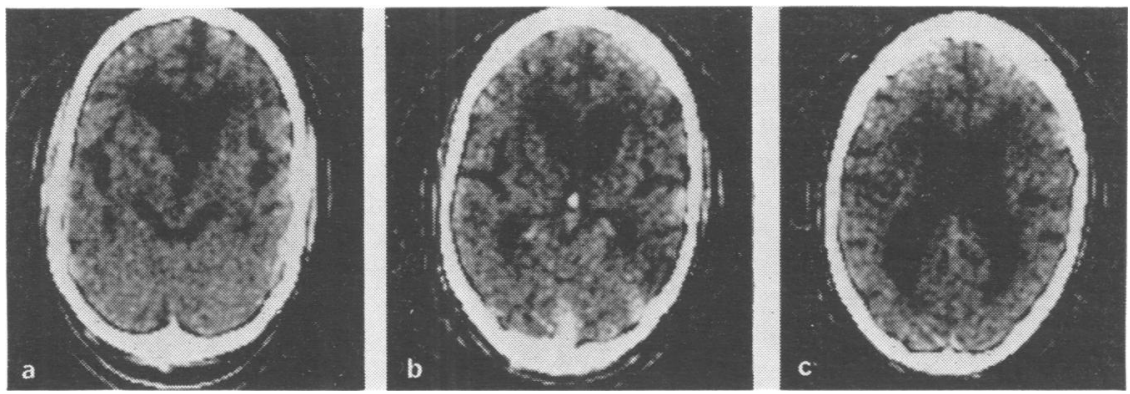

Fig 2 Reduced white matter attenuation, but showing unusually marked atrophic changes.

pressure of the two groups (group A mean 103, group B $105 \mathrm{~mm} \mathrm{Hg}$ ). Group A had mean systolic blood pressure of 171 compared with $188 \mathrm{~mm}$ $\mathrm{Hg}$ in group B. Five patients, all in group B, were on antihypertensive therapy (methyldopa); all had a diastolic pressure of at least $100 \mathrm{~mm}$ Hg. Eleven patients, all hypertensive, had documented evidence of peripheral vascular or cardiac disease. Five patients complained of headache; four of them were hypertensive. Among the 19 demented patients $16(84 \%)$ were hypertensive, $14(74 \%)$ having a diastolic pressure greater than $90 \mathrm{~mm} \mathrm{Hg}$, but the extent of WMLA was no greater than in the patients who were not demented.

\section{Discussion}

The association of periventricular WMLA with ventricular enlargement is a well known feature of hydrocephalus. In such cases the reduced attenuation probably represents transependymal fluid leakage, ${ }^{2}$ although cerebral oedema ${ }^{3}$ and demyelination have been suggested. Aside from the differences in ventricular dilatation and cerebral subarachnoid spaces in cerebral atrophy and hydrocephalus ${ }^{4}$ there are also differences between the distribution of reduced attenuation in the condition being discussed and that of PVL. ${ }^{3}$ In both conditions the frontal lobe was constantly affected, but on the one hand the cella media was involved in $54 \%$ of the atrophic group compared to $15 \%$ with periventricular WMLA in the hydrocephalic group and on the other, the occipital and temporal lobes were never affected in the atrophic cases compared with $7 \%$ and $13 \%$ respectively with hydrocephalus.

In some normal scans the frontal white matter is strikingly prominent apparently at least in part because of technical factors. This probably facilitates identification of reduced attenuation in this region, whereas the temporal regions may be difficult to assess as this area is prone to bone induced artefact. Such considerations may modify CT scan appearances in general but apply equally to all pathologies and should not influence differential diagnosis. The number of conditions in which low attenuation areas have been described in cerebral white matter is now large and the more prominent examples, most of which have no further similarity to our cases, are listed in table 2.

A further group of conditions is recognised in which a vascular pathophysiology is implicated and includes polycythaemia ${ }^{6}$ and venous thrombosis. $^{2}$ In such cases haematological studies and clinical features respectively usually make the diagnosis clear. We believe, however, that ancther group can be identified, in which the combined CT features of moderate cerebral atrophy and low attenuation areas in the deep white matter are seen in patients of relatively advanced age, who are usually hypertensive and often show clinical evidence of dementia.

None of our patients have died, and in the absence of morbid anatomical or histological correlation the pathophysiology of the condition remains speculative, but the highly significant correlation with vascular hypertension suggests a causal relationship.

In none of the patients was there any clinical or CT evidence of haemorrhage, or of any

Table 2 Causes of diffuse reduction in white matter attenuation

Defective myelination (leucodystrophy, spongiform degeneration)

Periventricular leucomalacia, prematurity

Metabolic and degenerative disorders (gangliosidoses, mucopolysaccharidoses, muscular dystrophy)

Infections (measles, mumps, SSPE, progressive multifocal leucoencephalopathy)

Demyelination of unknown aetiology (multiple sclerosis)

Systemic effect of metabolic disorder (hepatic coma, uraemia amyloid disease)

Trauma and toxins (irradiation \pm methotrexate)

Hydrocephalus, periventricular lucency

Cerebral oedema

Cerebrovascular disorders (see text) 
episodic course suggesting recurrent ischaemic events. It is well known that cerebral infarcts may leave no detectable residue on $\mathrm{CT}$, such regions being evident in only $20 \%$ of patients presenting with dementia due to multiple infarcts. $^{7}$

Diffuse WMLA may occur in hypertensive encephalopathy ${ }^{6}$ and has been shown in some cases to resolve after treatment of hypertension but in none of our patients was there a history of any episode suggesting this condition. An important feature of the low attenuation was its symmetry around the anterior horns and bodies of the ventricles. There are three conditions predominant in hypertensives patients which could possibly be associated with such a CT appearance: lacunar infarcts, Binswanger's disease, and état lacunaire et criblé.

Lacunar infarcts are often associated with clinical evidence of a stroke and are predominant in the pons, basal ganglia, and capsular regions, which appeared normal in our patients. It is extremely unlikely that lacunar infarcts widespread enough to cause the abnormality present in cur patients could have occurred without more clinical evidence of focal neurological upset.

It is unlikely that so-called Binswanger's disease is a clinical entity ${ }^{8}$ but it has been considered as a form of cerebral atherosclerosis. The clinical picture is that of slowly progressive dementia in patients "on the threshold of old age", and accompanied by episodes of focal neurological deficit. Histologically, white matter atrophy and demyelination are prominent. A characteristic feature is great enlargement of temporal and parieto-occipital regions of the lateral ventricles, but this was not a feature of our cases.

Atrophy occurring around the perforating arteries in the basal ganglia (état lacunaire) and in the deep cerebral white matter (état criblé) is found in hypertensive patients. They may have evidence of varying degrees of pseudobulbar palsy and dementia of insidious onset, although some have been asymptomatic. The condition is not typically associated with generalised atrophy, which would fit well with the relatively mild degree noted in our patients. We consider that état crible is the most likely explanation of the appearances in the patients we have described.

We gratefully acknowledge the co-operation of clinical colleagues of the National Hospital for Nervous Diseases, and also the secretarial assistance of Miss Susan Wassell.

\section{References}

1 Pasquini U, Bronzini M, Gozzoli E, Mancini P, Menichelli F, Salvolini U. Periventricular hypodensity in hydrocephalus: a clinicoradiological and mathematical analysis using computed tomography. Computer Assisted Tomography 1977; 1(4):443-8.

2 Kingsley DPE, Kendall BE. The value of computed tomography in the evaluation of the enlarged head. Neuroradiology 1978; 15:57-71.

3 Naidich TP, Epstein F, Lin JP, Kricheff II, Hochwald GM. Evaluation of paediatric hydrocephalus by computed tomography. Radiology 1976; 119:337-45.

4 Gado MH, Coleman RE, Lee KN, Mikhael MA, Alderson PO, Archer CR. Correlation between CT and radionuclide cisternography in dementia. Neurology 1976; 26:555.

5 Moseley IF, Radue EW. Factors influencing the development of periventricular lucencies in patients with raised intracranial pressure. Neuroradiology 1979; 17:65-9.

6 Kendal BE, Claveria LE, Ouiroga W. In: du Boulay GH, Moseley IF, eds. CAT in leukodystrophy and neuronal degeneration. European seminar on computerised axial tomography in clinical practice. Berlin: Springer-Verlag, 1976: 191-202.

7 Radue EW, du Boulay GH, Harrison MJG, Thomas DJ. Comparison of angiographic and CT findings between patients with multiinfarct dementia and those with primary neuronal degeneration. Neuroradiology 1978; 16:113-5.

8 Olszewski. Subcortical arteriosclerotic encephalopathy-review of the literature on the so-called Binswanger's Disease and presentation of two cases. World Neurol 1961; 359-74.

9 Binswanger $O$. Die Bergrenzung der allgemeinen proggressiven paralyse. Allgemeinen Zeitschrift für Psychiatrie 1895; 51:804-5. 